\title{
Have We Made the Progress?
}

\author{
K. S. Gopinath ${ }^{1}$
}

Published online: 10 September 2021

(c) Indian Association of Surgical Oncology 2021

Desk of the Editor Vol.12 Issue 3

$75^{\text {th }}$ YEARS OF INDIAN INDEPENDENCE DAY CELEBRATION

HAVE WE MADE THE PROGRESS?

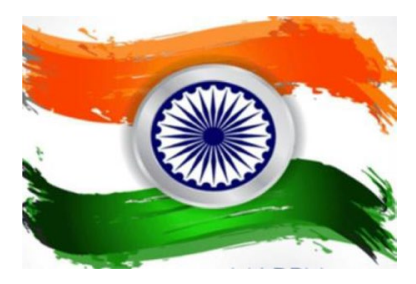

My dear colleagues,

Sending to all our authors, reviewers, readers, members of IASO, and editorial board of IJSO warm wishes on the occasion of celebration of 75th year of Indian Independence Day.

We are celebrating the 75th year of Indian Independence Day, which resulted in progress in Indian subcontinent in all walks of life. India became larger democratic country. Great people worked hard to bringing in change in the life of the people in the form of education, which helped for development of science and technology.

The cancer care has made slow progress over 75 years. In the first few decades after independence, the progress was slow. We use to walk behind everybody. Last two decades progress in medical education in the form of uniform pattern of training in undergraduate and postgraduate super specialty courses resulted in walking with everybody together across the globe.

Oncology is established as a specialty, and development of subspecialty like surgical, radiation, and medical oncology has resulted in establishing standard of care, practice of evidence-based medicine and implementation of utility of various national and international guidelines.

The progress in oncology has resulted in establishing many tertiary care centers both the government and from private, corporate-based with various models has resulted in practicing personalized medicine, precision therapy, at affordable cost.

K. S. Gopinath

ijso@iasoindia.in

1 Division of Surgical Oncology, HCG Cancer Hospital, Health Care Global Enterprises, Bangalore 560027, India
Though there is a need to improve in primary and secondary care. Tertiary care centers are established in metropolitan cities and tier II and tier III cities. Now there is a need for many such centers across the country to integrating them to develop medical education systems. We have to look at use of Indian system of medicine into modern medical education at various levels.

Now we have developed our own models for training which are need based. Today we have to develop the curriculum for Indian solutions to Indian problems. With availability of various schemes in the form of health insurance resulted in giving quality care to our large population. Both government and non-government schemes are available to the population.

Importance given to innovation in research at various levels which should be need based.

Progress in medical research still needs to be enhanced. Today there is a need for establishing genomic data bank so that every institution should have tissue repositories, clinical research centers with that we can exploit biology in the management of oncological diseases.

We dedicate the issue of IJSO vol. 12 issue 3 to all people who dedicated there life to achieve independence and to the scientist who involved in progress of the nation.

Jai Hind.

Dr. K. S. Gopinath

Chief Editor/Chairman IJSO

Publisher's Note Springer Nature remains neutral with regard to jurisdictional claims in published maps and institutional affiliations. 